\title{
O Codigo Eleitoral
}

\section{Preleção inaugural do curso de doutorado na Faculdade de Direilo de São Paulo}

\section{A. de Sampaio Doria}

No curso de doutorado que ora aqui se instala, me coube imerecidamente a honra de analisar, este ano, algumas das mais altas teorias sôbre o Estado. Compreendo a dureza da tarefa, a responsabilidade que assumo, e os riscos a que me exponho. Correm as horas mais sombrias, por que jamais passou a nossa terra. Ao terremoto das violências politicas, que subvertem o mundo, não nos logramos escapar ilesos. Em grande parte é nossa a culpa, porque teimavamos em manter o regimem das falsidades, o regimem das improbidades administrativas, o regimem da escravidão politica. E resultados fatais da nossa teimosia, ei-los na incerteza, na inquietação e nos perigos dos dias que vivemos.

$\mathrm{Na}$ trajetoria que percorrem os Estados, de sua gênese ao seu florescimento, se colhem, a olhos vistos, duas lições que nos fazem meditar. A primeira é que nenhuma civilização se criou jamais sem lutas, a liberdade não se conquistou nunca sem revoluções. E a segunda é que as revoluções em si não curam os males contra os quais explodiram; não sabem sinão destruir; é a sua sina.

As gerações que se revoltam, sofrem ainda mais, seus membros se entredevoram, e terminam quasi sempre queimadas nas 
fogueiras que ateiaram. Só as gerações seguintes aproveitam os beneficios que as revoluções possam trazer, e isto mesmo, quando adquirem a sabedoria prática de as evitar.

Não tenhamos ilusões. O desmantelamento do Estado, entre nós, vai ter convalescença longa e dificil. Quem, neste momento, poderá, ou saberá reconstruir, sôbre os escombros da Republica envelhecida e envilecida, o Brasil de amanhã ? Arquitetam-se teorias e teorias sôbre o Estado. Heresias, intrepidas como a ignorancia, desafiam monstruosidades que causam pena. E quarenta milhões de criaturas humanas, e quatrocentos anos de civilização se acham, neste momento, á orla de experiencias economicas, em que outros já se arruinaram, e de aventuras politicas, em que outros já se escravizaram, e se vão aniquilando cada vez mais.

A ciência do Estado não se improvisa. Não é materia arbitraria, senão para hóspedes que a deletreiem, ou observadores de passagem que olham sem ver. Os princípios fundamentais do direito público sobrenadam sempre ás paixões politicas, por mais arrogantes, que os desconheçam ou os neguem. As tempestades passam, e eles ficam, eternos na sua pureza, como os raios dourados do sol, quando o céu se desanuvia.

Para a reconstrução do Estado, no Brasil, invoca-se uma indole brasileira, uma tradição brasileira, a realidade brasileira.

Mas que é esta realidade, fóra das realidades humanas?

A realidade brasileira, em materia politica, eram, principalmente, as eleições falsas, a hipertrofia do presidencialismo; eram as concessões escandalosas, e a advocacia administrativa; eram as loucuras tinanceiras, e o desrespeito aos tribunais; era, em quasi tudo, a tirania: os caprichos do arbitrio sôbre a imparcialidade das leis, a inspiração dos egoismos sobre os interesses gerais.

E será isto o que se deseja consolidar, quando se fala em realidade brasileira?

O de que se precisa, é, exatamente, sair da realidade brasileira no que ela tem de imprestavel, no que ela tem de abusivo; no que ela tem de deshumano. O mal dos males, na organização do Estado, entre nós, era a falsa representação do povo 
soberano, na investidura do poder e na legitimidade do seu exercicio. A Constituição de 24 de fevereiro ainda não foi ultrapassada, em sabedoria jurídica, precisão de linguagem e senso politico, nem pelas mais modernas, como a da Alemanha e a da Espanha. No entanto, vegetou quarenta anos, degenerada e maltrapilha, sôbre uma roupagem de realeza, de pompa e suntuosidade. Eram prerogativas, para cuja obtenção, o povo não tivéra lutas e nem sofrimentos, passo a passo, através dos seculos. Outorgaram-lhas pela mão de um genio. Mas esqueceram de lhe proporcionar os meios de a fazer respeitada e cumprida. Foi como se fadas gracejadoras ensejassem a náufragos em alto mar o mais perfeito hidroplano, mas esquecessem, ao mesmo tempo, a essência com que podessem voar.

$\mathrm{Na}$ escura noite em que a revolução mergulhou o Estado brasileiro, neste vasto deserto de homens e de ideas, em que ela se debate, hoje apenas cintila, e muito ao longe, a mortiça luz de uma esperança vaga. E' a promessa de que se vái, com o Codigo Eleitoral, abrir o primeiro caminho da reconstrução nacional.

Sejam quais forem as preferencias indigenas, que venham a matizar o Estado, princípios ha imprescritiveis na legitimidade do poder de dar ordens incondicionadas. Entre todos eles, o que ha de prevalecer para sempre, entre as raças privilegiadas, é o consentimento dos governados na constituição e no exercício do poder. O que legitima o poder, não pode ser, ciêntificamente, a origem divina. Nem tão pouco ha de ser ele uma questão de fáto apenas, e mais nada. A legitimidade real do poder estả inteira no consentimento dos governados.

Ora, este consen iimento só ha um meio por onde vingue. E' o regimen da tepresentação popular. E' a primeira das preocupações nos Estados onde os homens sejam criatuı as livres.

Pena é que levassemos mais de ano, para compieender este princípio dos princípios em materia de govêrno, e só agóra se tenha o Codigo Eleitoral, ha dias em vigor.

Foi o primeiro passo para o retorno ao regimem da lei. Mais que isso. Foi a "Carta de alforria» dada aos brasileiros, na frase do então Ministro da Justiça. Se a Constituição de 91 
tivesse tido, na sua execução, uma lei como o Codigo decretado, o Brasil não estaria reduzido, hoje, á dolorosa situação de quasiChina deflagrada. As leis eleitorais da Republica decaída pareciam de proposito feitas, para falsear a representação da soberania, para sufocar as apiraçõs populares, para emudecer a nação desarmada e descontente. A nação era, na esfera politica, sem tirar nem por, uma senzala.

Mas com a instituição do Codigo Eleitoral de 24 de fevereiro nunca mais voltarão ao poder os escravocratas políticos. e os falsários da soberania.

Vêde porque.

O saneamento que se vái operar, começa na constituição do corpo eleitoral. O que serviu a Republica de 89 , não tem quasi qualificação na linguagem da decência politica. A grande maioria dos cidadãos cultos se abstinha de qualificar-se eleitor. E a maioria destes era gente inculta, ou venal, ou timida ou extrangeiros a que se dava carta de cidade para fins eleitorais.

Compreende-se que, com semelhante eleitorado, as eleições fossem o que eram, e os caudilhos se entronizassem no poder, como em casa propria.

Mas o Codigo Eleitoral vái realizar, aqui, a primeira maravilha. Começa por obrigar ao alistamento os homens capazes. Considera-os qualificados compulsoriamente. Os magistrados, os militares, os advogados, os professores, os medicos, os engenheiros, os comerciantes e industriais matriculados, os reconhecidamente idoneos, já se acham qualificados por lei. E' a grande maioria dos instruidos, dos mais responsaveis, que se abstinham de alistar-se, e que passam agóra a constituir o sistema nervosodo novo corpo eleitoral.

Mas não se contentou com esta invocação o Codigo da Liberdade. Tendo anulado todos os alistamentos anteriores, não per mite que voltem ao corpo eleitoral os ignaros, os incapazes ao menos de ler e escrever. Sabe-se que, nos alistamentos em voga, os semi-analfabetos, pelo menos nos sertões, eram a massa decisiva. De uma cidade de onde o eleitorado passava de quatro mil conta-se que não tinha quatrocentos cidadãos alistaveis. Pois bem, o Codigo Eleitoral exige que o alistando escreva de seu proprio punho o seu requerimento; e o tabelião 
terá de lhe reconhecer a letra e a firma. $\mathrm{E}$ ai do tabelião que as reconhecer falsamente! Por um processo rapido e seguro, o menos que perde, é o seu cargo.

Foi o primeiro passo de saneamento: de um lado, a exclusão da ralé interesseira, e, do outro, o chamamento ás urnas dos homens de conciência, que viviam alheiados ás traquibernias da fraude. A nação que pensa, a nação que sabe, a nação que quer, vái ser a vóz que escolhe, a vóz que fiscaliza, a vóz que dirige.

O Codigo Eleitoral não parou, entretanto, nesta primeira providência. Adotou o voto secreto. Era a grande aspiração insatisfeita, a que a cegueira dos nossos-senhores não dava quartel. $O$ regimem então vigente era o do eleitor que recebia cedula á boca da urna. Por todos os meios, fiscalizavam o voto, para aliciar votantes. Clamava-se contra a escravidão politica. Invocava-se o exemplo das nações cultas, onde o voto secreto se incorporou, ha mais de cem anos, nas suas instituições, como, entre nós mesmos, com a lei de 13 de maio, o princípio da igualdade de todos perante a lei. Era tudo em vão. Se mais não fizesse, valeria a pena ter-se feito a revolução, para implantar $o$ voto secreto.

O processo do sigilo que o Codigo consagrou, parece não deixar brecha por onde se insinue a fraude. O eleitor que já não é aquela criatura timida, inconciênte, ou venal, que os cabos eleitorais agraciavam, intimidavam e manejavam, vái votar livremente. Ninguem poderá devassar a escolha que faça, na hora em que vota. Naquele instante, em que, dentro da saleta insulada, coloca a sua cedula na sobrecarta autenticavel, faz o que quer. Naquele instante, é absolutamente soberano. $\mathrm{O}$ seu voto é realmente a expressão exata da sua vontade. Generalize-se o fáto. Por todo o país, o cidadão vota como quer. O resultado último ha de ser, por fôrça, a expressão fiel, legítima, autentica, da conciencia nacional. Os eleitos recebem o poder que vão exercer, da vontade do povo, sôbre quem ele se vái aplicar. E o poder de dar ordens não podia, então, ser mais legítimo, pois se origina do consentimento expresso dos cidadãos alistados.

O Codigo ainda não parou nesta segunda providência. 
Que valeria o voto livre e conciente, se não fosse apurado? A prática das mesas eleitorais era a traude mais cínica. Atas fabricadas de vespera. Outras se lavraram na hora, a bom grado dos chefes, aumentando-se ou diminuindo-se, como se desejasse, a votação de candidatos. Até a em tempo se recorria, para substituir a votação real pela votação das atas. Era um dos mil modos de furtar, que tirava aos diplomados da traude a legitimidade do poder que iam fruir.

Mas o Codigo de 24 de fevereiro procurou fechar todas as portas ao arbitrio na contagem dos votos. Note-se que os eleitores já são homens livres e capazes. E, agóra, o que cair nas urnas, vái prevalecer. O Codigo, para isto, permitiu a fiscalização dos partidos nos atos eleitorais; permitiu a veriticação da identidade dos eleitores pelo confronto das impressões digitais; deu ás seções receptoras de votos presidencia imparcial; è a apuração que se fazia quasi sempre á noite, já fatigados os mesarios e fiscais, vái ser operada, na capital de cada Estado, por tribunais de justiça. As urnas serão transportadas até o edificio onde eles funcionam, e, aí, na presença de todos os interessados se procederá, com rigor, á contagem verdadeira dos votos. Liquida-se, primeiro, a identidade contestada dos eleitores, e, depois, procede-se á apuração geral.

Como será possivel, agóra, a falsificação habitual na contagem dos votos? Se até os juizes togados, homens de cultura jurídica e comprovada idoneidade moral, se conspurcassem na fraude de uma apuração mentirosa, ante os olhos dos interessados, que protestariam; se tamanha ignominia se viesse a verificar, então estaria tudo perdido, já não haveria para quem recorrer. Nas organizações humanas ha limites que se não transpõem.

Mas o Codigo ainda prossegue. Raramente, na realidade brasileira, se processava uma eleição razoavel. Era, aqui, ou ali, a opinião pública que rompia a superficie de gelo ou a crostà dura das opressões oficiais. Mas os diplomados ficavam á mercê dos reconhecimentos arbitrarios no congresso. Era uma máquina terrivel, caprichosamente montada, para que imperasse, onipotente, a vontade dos presidentes da Republica. Inventou-se no regimen presidencial, a figura exotica de lider, por cuja bôca 
o. parlamento recebia as ordens de reconhecer por eleitos quem tivesse as graças do presidente. $O$ congresso não apurava, elegia: substituindo criminosamente a nação soberana.

Pois, o Codigo Eleitoral de 24 de fevereiro deu o golpe de misericordia a este ultimo reduto da fraude. Quem de agóra em diante, vái diplomar são os tribunais de justiça eleitoral. Si houver contestação a diplomas, ainda é o Tribunal que sentenciará. Trata-se, evidentemente, de uma questão judiciaria, ainda que com aspeto politico, e para fins políticos. A essência de uma contestação de diplomas é judicial. Numa bôa separação de poderes, não se compreende que subsista a judicatura do parlamento para taís pleitos. E' uma destas rotinas que a realidade brasileira se encarregou de escalpelar e condenar para todo o sempre. De agóra em diante, se não tornarmos ás práticas. abusivas de uma falsa separação de poderes, já não se rasgarão diplomas de eleitos, criando, mais que tudo, a hipertrofia de poder nas mãos dos presidentes da Republica.

Não contente de ter organizado, com a perfeição possivel, o aparelho por onde prevaleça o voto conciente e livre, o Codigo Eleitoral, de 24 de fevereiro, instituiu a representação proporcional. A constituição republicana já ordenava a representação das minorias. Mas esta, com exeção de no Rio Grande do Sul e no Distrito Federal ou pouco mais, só se positivava, quando e na medida do que entendessem os govêrnos locais. As últimas eleições de S. Paulo, e era S. Paulo, deixaram bem patente o arbitrio de quem pode. As minorias, e uma delas consideravel, não se puderam fazer representar.

Ora, o ideal é que toda a nação se represente, toda consinta, não tacita, mas expressamente, na delegação, a que lhe obrigam as contingências da vida, do exercício da sua soberania inalienavel. A nação pensa, fala e decide pelo seu corpo eleitoral. Não é de esperar que todos pensem da mesma fórma. Em torno deste ou daquele credo político, se congregam os cidadãos. E' aqui um problema economico para o qual se pleiteiam soluções, formando-se agrupamentos que se combatem, de individualistas, ou de liberais, de socialistas, e, até, de comunistas. E', ali um problema político, como a federação ou o unitarismo, o regimen parlamentar, ou o sistema presidencialista, dividindo os cida- 
dãos ativos nas conviç̧ões do que melhor lhes parece convir ás instituições e á patria. Em linhas gerais, anseiam uns por tudo reformar para maior liberdade dos individuos e maior eficiência dos serviços públicos. E' a corrente liberal. 'Teimam outros, porêm, em respeitar, como está, a organização social e o aparelhamento político, ou reformá-los, para fortalecer ainda mais a autoridade do Estado. E' a corrente conservadora. De qualquer fórma as opiniões se partidarizaram. E monte a quanto montar a maioria das opiniões políticas, disciplinadas, não é justo que só ela governe. O justo é que cada qual se represente na medida do que fôr e puder.

O princípio majoritario puro e simples é escravidão das minorias pelas maiorias. A proporcionalidade é a justiça evidente. Ouví a Barthelemy: "Cinco meninos, da mesma familia, se encontram reunidos em torno de uma torta. Tres dentre eles, vestidos de azul, declaram aos dois outros vestidos de vermelho: - Nós somos tres, e vocês não são mais que dois. Nós temos a maioria. Logo nós vamos comer toda a torta, e vocês nada. Não pode ser, replicam os dois meninos vermelhos. Nós somos cinco, dividamos a torta em cinco partes, e cada um terá a sua parte. - Disputa. Batalha. Vós sois chamados a resolver o conflito. Dareis razão aos que pleiteiam para que cada um tenha a sua parte, seu quociente? E' que sois proporcionalista".

Pois o Codigo eleitoral, de 24 de fevereiro, acudiu a esta necessidade com o mais perfeito dos sistemas conhecidos. Suponde, em S. Paulo, 200 mil eleitores ativos, cidadãos não apenas alistados, mas que comparecem ás urnas. Admitamos dividirem-se eles em 3 correntes políticas, á parte opiniões avulsas. A maioria é de $60 \%$ - 120 mil votantes. Ha uma minoria de $30 \%-60$ mil partidarios fieis. E outra minoria de 10\%: 20.000 devotados ás correntes extremistas. No regimen que a revolução destruiu, a maioria de $60 \%$, com rodizios, ou sem eles, elegia sem partilha para todos os lugares a preencher, como os ties meninos vestidos de azul em relação á torta.

Vem, porêm, o Codigo, e, queiram ou não queiram as maiorias, a representação será proporcional ás opiniões como é de justiça evidente, e isso automaticamente, mecanicamẹte, neces- 
sariamente. Perfilhou, para este resultado ideal, maravilhoso sistema do quociente eleitoral e do quociente partidario.

$O$ sistema funciona do seguinte modo.

Em primeiro lugar, devem os partidos registrar nos tribunais regionais, as listas dos seus candidatos. Sem este registro, nunca se poderia saber a percentagem de eleitores de cada parcialidade. $\mathrm{Na}$ apuração, é que se pode cientificar, pelo numero de chapas de cada partido, a votação que cada um alcançou. Eis a primeira providência para a representação proporcional.

A segunda consiste em instituir a votação simultanea de dois turnos, primeiro e segundo. Considera-se votado no primeiro turno o candidato cujo nome figure em primeiro lugar na cedula. E' o candidato preferido pelo eleitor. O eleitor pode votar em tantos nomes, quantos são os logares a preencher, mais um. $\mathrm{O}$ primeiro nome se considera votado em primeiro turno, e, no segundo, os demais. E' claro que cada partido faz variar o primeiro nome tantas vêses, quantos imagina que vái eleger.

$E^{\prime}$ de conveniencia que contemple, no primeiro turno, com mais do que supõe eleger. Primeiro, porque não sabe ao certo, em todo o Estado, qual vai ser exatamente a sua votação, e não ha de eleger menos, só porque reduziu o numero de seus candidatos em primeiro turno. Segundo, porque não perde, não desperdiça voto nenhum no primeiro turno, como se verá.

A terceira providência consiste em se haver por eleito, no primeiro turno, quem quer que obtenha numero de votos igual ou acima do quociente eleitoral. O quociente eleitoral é o que resulta da divisão do numero de eleitores que votaram na eleição, pelo numero de lugares a serem providos. Se, na proxima eleição, S. Paulo levar ás urnas 200 mil eleitores, e tiver de eleger, como é de equidade, 40 representantes no minimo, o quociente eleitoral será 5.000 , obtido na divisão de 200000 por 40 . E' o numero minimo necessario para ser eleito.

Ora, a maioria que ha pouco, imaginamos, de $120 \mathrm{mil}$ eleitores, pode distribuir os seus votos por 24 candidatos. $\mathrm{O}$ vigesimo quinto, se houvesse, já não se elegeria, porque já não alcançaria o quociente eleitoral. No caso, 5 mil votos. 
Tambem, a primeira minoria, de 30 por cento: $72 \mathrm{mil}$ eleitores, elegeria doze candidatos. E' o numero que se obtem, dividindo-se os seus 72 mil votantes pelo quociente eleitoral: 5.000 .

E a minoria da esquerda, com os seus 20 mil apostolos, $10 \%$ do eleitorado ativo, consegue eleger 4 representantes. E' o numero alcançado na divisão dos seus partidarios que votaram, 20.000 pelo quociente eleitoral: 5.000 .

Acontece, porêm, que nenhum partido sabe de antemão qual vái ser a porcentagem exata entre a sua votação e a votação total da circunscrição eleitoral. Figuremos um caso concreto, sôbre os $10 \%$ da minoria trabalhista ou comunista. São 40 os elegendos. 200.000 o eleitorado inteiro que votou. E $20 \mathrm{mil}$ os partidarios da minoria. Admitamos que ela supôz alcançar 40 mil vocos, e distribuiu por oito candidatos os seus votos no primeiro turno. Mas como só lhe consagraram a chapa 20000, metade do que sonhou, coube por media aos seus oito candidatos em $1 .^{\circ}$ turno 2500 votos. Nenhum atingiu o quociente eleitoral, que, no caso é de 5 mil. E, por esta fórma, esta minoria deixaria de eleger por êrro de calculo. E a representação já deixaria de ser proporcional.

O Codigo de 24 de fevereiro não permitiu esta injustiça. Tem cada agrupamento de eleitores, classes ou partidos, que se representar proporcionalmente aos seus eleitores. Daí a quarta providencia: o quociente partidario.

O quociente partidario é o numero que se obtem, dividindo-se pelo quociente eleitoral o numero de eleitores que cada partido tenha levado ás urnas. Se um agrupamento alcançou 20 mil votos, e se o quociente eleitoral é cinco mil, o quociente partidario é quatro, obtido na divisão de 20.000 por 5.000 .

A outra minoria a de 60 mil votos, já tem um quociente partidario mais alto. O quociente eleitoral é invariavel. E' o que resulta, dividindo-se o numero total de votantes pelo numero de elegendos. $\mathrm{Na}$ hipotese admitida, o quociente eleitoral é cinco mil. Já o quociente partidario é o numero que se encontra, na divisão do numero de votantes de um partido, pelo quociente eleitoral. A minoria de $30 \%$ tem, por quociente partidario, doze. 
E a maioria de $60 \%$ tem, por quociente partidario 24 . O Codigo Eleitoral, adotando o quociente partidario, determinou que estão eleitos no primeiro turno, tantos candidatos na chapa de cada partido, quantos, entre os mais votados naquele turno, igualarem o quociente partidario. Pode nenhum dos votados em primeiro turno ter alcançado o quociente eleitoral, e não obstante, a lei os considera eleitos.

Aquela minoria extremista que votasse, por êrro de cálculo, no primeiro turno, em 7 candidatos, quando não tinha força para eleger mais de 4, nem por isso deixou de eleger os seus quatro representantes.

Tudo isto, porêm, podeis dizer-me, é bonito no papel. Tambem tinhamos a mais perfeita constituição do mundo, e viviamos sob o disfarce constitucional de uma ditadura. A lei é uma cousa, e a realidade é outra.

Efetivamente, não basta terem-se leis bem feitas. Eu creio até que alguns dos adeptos do Codigo da liberdade não alcançaram, em toda a sua extensão, o que ele vae produzir: não mediram bem os seus efeitos saneadores. Eles, por certo endurecidos no ceticismo, tambem não creiem muito na sua eficacia, e, por isso, é que lhe deram a sua adesão meio forçada. Porque, com a aplicação do Codigo, tambem eles não se hão de sentir muito seguros, pois nunca mais haverá, no país, representantes sem votos, nunca mais se elegerá por atas falsas, por diplomas graciosos, pelo compadrio dos reconhecimentos.

De nada valeria o Codigo, por mais sabio e previdente que lhes fossem as disposiçõ'es, se não se criassem, para a sua execução os tribunais de justiça privativos, em materia eleitoral. A justiça antiga era falha, parcial aqui, displicente alí. A mentalidade indigena ainda não se penetrou da identidade essencial entre delitos comuns e delitos eleitorais. O Codigo reconheceu este mal, e providenciou, criando uma justiça especial com todas as garantias da magistratura comum. As normas processuais foram simplificadas. Os partidos se fiscalizam reciprocamente. São julgadores os magistrados do proprio tribunal. As penas, as mais rigorosas.

Se, não obstante, ainda falhar esta judicatura, se tres ministros dos tribunais mais al tos das justiças locais, e, juntamente, 
o juiz federal da segunda ou primeira vara e, mais, tres cidadãos de notavel saber juridico e idoneidade moral, se falharem todos no cumprimento da lei e do dever, é que somos desgraçadamente uma raça de tarados. Já não haveria, então, para quem apelar. Seriamos indignos da liberdade.

Mas injuria tamanha aos nossos juizes e aos nossos juristas, ninguem que tenha senso, ousará lançar. Com todos os defeitos e sentimentalidades da raça, o Brasil tem uma historia de paz e de justiça como poucos povos. Erros lhe têm sobejado; mas, aqui mesmo, a reação tem surgido, e a emenda ha de vir. Não ha povo que não tenha tido, na sua historia, desvios e crimes de todos os matizes. O que é essencial para que a civilização não pereça, é a reprovação imediata, e a punição severa. Só não cometeria erros e deslizes um povo de semideuses. Não aspiremos a tanto. Contentemo-nos em ser o que somos.

Os tribunais farão do Codigo Eleitoral a carta de alforria dos brasileiros.

Estão de parabens os revolucionarios de visão e desinteresse. Revoltaram-se, pelo verbo que preparava as conciencias e pelas armas que arrazaram as cidadelas dos oligarcas, revoltaram-se uns e outros contra o que existia de mal. E o que existia de mal era, em sumula, a espoliação da soberania inalienavel ao povo desarmado, o confisco á nação do direito de se governar a si mesma. Mas quem se revolta contra certo mal, é porque não quer a permanencia desse mal. Se o mal era o govêrno de caudilhos á revelia dos governados, o mal só desaparecerá quando os governados escolherem seus governantes. Quanto mais tardar o dia em que se efetúe esta escolha, tanto mais se prolongará o mal que se combatia.

Substituirem-se mandões, uns por outros, sem que a nação fale pelas urnas, é continuar a nação como estava, esbulhada da sua soberania imprescritivel, da liberdade de criar ou moldar seu proprio destino.

$\mathrm{O}$ intuito de só se poderem resolver os grandes problemas nacionais com poderes discrecionarios, é afronta á nação com a pecha de que ela é incapaz de se dirigir por si mesma.

O espiríto revolucionario ou consiste em restituir á nação a soberania de seus destinos, e reluz entre cintilaçõis de gloria, 
ou se reduz a substituir usurpadores por usurpadores e é um crime. E a unica fórma de reintegrar-se a nação no govêrno de si mésma é convoca-la para as deliberações solênes sem tutelas.

O Codigo Eleitoral foi a promessa do primeiro passo. Já está em vigor. Vão reunir-se agora os tribunais, e começará o alistamento. E, depois, nada impede a convocação da constituinte para que se reorganize o Estado no Brasil.

Tenha, então, Deus piedade dos brasileiros. Que mãos iconoclastas não destruam os princípios cardeais da Constituição de 91. Façam-lhe as adições e as substituições que o patriotismo inspirar.

Mas não a esvasiem do espírito jurídico e da sabedoria política em que foi vasada. Todas as obras humanas podem aperfeiçoar-se. Mas não as aperfeiçoa o solapamento das bases em que se apoiem.

Nunca foi mais oportuno que agóra o exame, nesta Faculdade, das teorias sôbre o Estado. O mundo se debate como tomado de uma grande febre, sem saber por onde orientar-se. A vasa das convulsões que o sacodem, já nos queima em carne viva. Tenhamos juizo, condenêmos as inovaçõis ideologicas mal digeridas, e mantenhamos custe o que custar, as tradições juridicas dos nossos maiores. 